\title{
Improving Social Initiations in Young Children with Autism Using Reinforcers with Embedded Social Interactions
}

\author{
Robert L. Koegel · Ty W. Vernon · Lynn K. Koegel
}

Published online: 9 April 2009

(C) The Author(s) 2009. This article is published with open access at Springerlink.com

\begin{abstract}
Children with autism often exhibit low levels of social engagement, decreased levels of eye contact, and low social affect. However, both the literature and our direct clinical observations suggest that some components of intervention procedures may result in improvement in child-initiated social areas. Using an $\mathrm{ABAB}$ research design with three children with autism, this study systematically assessed whether embedding social interactions into reinforcers, delivered during language intervention, would lead to increased levels of child-initiated social behaviors. We compared this condition with a language intervention condition that did not embed social interactions into the reinforcers. Results indicated that embedding social interactions into the reinforcers resulted in increases in child-initiated social engagement during communication, improved nonverbal dyadic orienting, and improvements in general child affect. Theoretical and applied implications are discussed.
\end{abstract}

Keywords Social engagement .

Pivotal Response Treatment · Dyadic orienting .

Social intervention

R. L. Koegel $(\varangle) \cdot$ T. W. Vernon · L. K. Koegel

Department of Counseling, Clinical, School Psychology,

Gevirtz Graduate School of Education, Koegel Autism Center,

University of California, Santa Barbara, CA 93106-9490, USA

e-mail: koegel@education.ucsb.edu

T. W. Vernon

e-mail: tyvernon@education.ucsb.edu

L. K. Koegel

e-mail: lynnk@education.ucsb.edu

\section{Introduction}

Social deficits are some of the primary diagnostic characteristics of autism (APA 2000; Harris and Weiss 2007; Joseph and Tager-Flusberg 1997; Kanner 1943; Mundy and Sigman 1989; Volkmar and Klin 1994; Wimpory et al. 2000; Zwaigenbaum et al. 2005). These deficits can manifest themselves in a variety of areas, including impairments in joint attention, decreased levels of eye contact, and a restricted affective range. Because difficulty engaging with others may persist throughout the lifespan, a large number of studies have been focused on improving social areas in early childhood. For example, coordinated eye contact behaviors, such as joint attention and dyadic orienting, have been targeted in early intervention research (Jones et al. 2006; Leekam and Ramsden 2006; Warreyn et al. 2005; Whalen and Schreibmen 2003; Whalen et al. 2006). These early social behaviors have been especially important to address, as they appear to be prerequisites for typical child development (Charman et al. 2003; Mundy et al. 1990). Without such intervention, children with autism may fail to develop a history in which social interaction is considered motivating or reinforcing over time, thus limiting their ability to develop close friendships and relationships in later years (Koegel and Lazebnik 2009).

A number of empirically supported interventions have been successful at improving the symptoms of autism (e.g., Koegel and Koegel 2006; Lovaas 1987; Prizant et al. 2006; Yoder and Stone 2006) and some strategies within current intervention procedures show particular promise in improving social functioning. For example, interventions that incorporate natural rewards result in strengthening the response-reinforcer relationship and therefore are especially helpful in encouraging social communication (e.g., Koegel and Koegel 2006; Koegel et al. 1987, 1999; McGee 
et al. 1999). That is, reinforcers that are logically related to the outcome of a chain of behaviors, have been shown to be more effective than using arbitrary, unrelated reinforcers in teaching tasks. An example of this procedure was described in an early study by Williams et al. (1981), in which a child was provided with an edible reinforcer found within a container upon successfully opening the lid, as compared to a child being handed an edible reinforcer after opening an empty container. In both conditions, the reinforcer was identical; however, only in the first condition were the child's actions naturally and integrally related to the outcome. Additional research has demonstrated that using a direct, response-reinforcer relationship increases the target child's motivation, rate of responding, acquisition of target behaviors, and affect as well as decreasing untreated disruptive behaviors (Goetz et al. 1979; Koegel et al. 1992; Koegel and Williams 1980; Williams et al. 1981). This has been described in the literature as using natural reinforcement (cf., Skinner 1982), and appears to be especially important for children with autism (Koegel et al. 1987).

An empirical question that remains is whether some types of natural, direct reinforcement could be used to improve child-initiated social behavior. For example, behavior therapies frequently incorporate social interaction within their contingencies; however, these components have not been systematically assessed to determine their effect on child behavior. Therefore, the purpose of this study was to evaluate a specific therapy componentembedding social interaction into the reinforcer-in a naturalistic language intervention context. We specifically examined this effect on child-initiated social behaviors, including social engagement during communication, nonverbal dyadic orienting, and general child affect.

\section{Method}

\section{Participants}

Three young children diagnosed with autism (ages 3:2, 3:3, and 3:5) participated in this study. All three children were diagnosed by outside agencies using the diagnostic criteria of the DSM-IV-TR (APA 2000) and were referred to our Center for intervention services. The children had no reported comorbid conditions or medical problems. Our Center confirmed their diagnoses through a combination of standardized assessment measures, including the Autism Diagnostic Observation Schedule (ADOS; Lord et al. 2000) and the Autism Diagnostic Interview-Revised (ADI-R; Lord et al. 1994), informal parent interviews, and direct child observations. The selection criteria for participation included: (1) a chronological age under 5 years; and (2) the presence of persistent social deficits in eye contact. Persistent social deficits in eye contact were defined as lack of eye gaze (i.e., eye gaze $<5 \%$ of the time in videotaped probes) with familiar adults across contexts (play and daily routines). This criterion was verified during the initial meetings with the participant families during a least two separate parent-child videotaped observation probes during natural routines in the family home. The first three children referred to our Center who met the inclusion criteria were selected for participation in this study. Parents of all three children signed approved IRB consent forms for participation in the study, and families were not paid to participate. There was no attrition.

\section{Child One}

Child One was 3 years, 2 months old at the start of the study. He had a repertoire of about ten functional words that were only used for behavior regulation functions, such as requesting toys or food. Child One had a long history of disruptive behavior that included aggression towards his parents and care-providers, lengthy tantrums, and selfinjurious behavior (SIB), particularly when others tried to interact with him. Child One's Vineland Adaptive Behavioral Scales (VABS; Sparrow et al. 1984) Adaptive Behavior Composite age equivalence was 1;9. His Social Domain age equivalence was 1;6, and his Communication, Daily Living Skills, and Motor Skills Domain age equivalences were $1 ; 2,1 ; 8$, and 2;9, respectively. Socially, he did not show affection towards familiar people, did not address familiar people by name, nor did he laugh or smile appropriately in response to positive statements.

\section{Child Two}

Child Two was 3 years, 3 months old at the start of the study. At the start of this study he had a repertoire of $\sim 75$ words and had just begun to combine words. Child Two exhibited neutral affect (failure to show pleasure or displeasure in response to others), no eye contact, and social avoidance (such as leaving the area) when presented with language opportunities. Child Two's VABS adaptive behavior composite age equivalence was 1;5. His socialization domain age equivalence was $0 ; 6$, and his communication, daily living skills, and motor skills domain age equivalences were $1 ; 8,1 ; 0$, and 2;6. Socially, Child Two did not show interest in other children, did not show affection towards his parents, and did not engage in any simple interaction games with others.

\section{Child Three}

Child Three was 3 years, 5 months old at the start of the study. He had five functional words ("go," "ball," "more," "swing," and "blanket") that he used only when 
prompted. He was described by his parents as "always in his own world," and demonstrated neutral affect and no eye contact across settings and activities. Child Three's VABS adaptive behavior composite age equivalence was 11 months. His socialization domain age equivalence was under 1 month. His communication, daily living skills, and motor skills domain age equivalences were $1 ; 2,1 ; 1$, and $1 ; 5$. Socially, he did not look into the face of his caregivers, inconsistently responded to the voice of his mother, did not show interest in others, and did not play social games.

\section{Design}

An ABAB design (Barlow and Hersen 1984) was used to assess the differences between the two treatment conditions (the non-embedded and embedded social conditions; described in detail below). An alternating treatments component was added during Child Two's participation, in which the child was exposed to alternating conditions within the same probe during the final two intervention sessions. This allowed us to assess the importance of the variable within the types of conditions that occur naturally in therapy sessions, where both embedded and nonembedded types of interactions often may occur.

\section{Clinician Training}

Intervention for Children One and Three was implemented by graduate student clinicians and for Child Two by his parent with feedback from a graduate student. In order to insure equivalence of intervention in the two conditions, all participating clinicians were required to meet fidelity of implementation (above 80\%) in the Pivotal Response Treatment procedures in five areas shown in the literature to be important for effective intervention, including: (1) providing the child the opportunity to select preferred stimulus items; (2) presenting a clear opportunity for the child to make a verbal attempt; (3) reinforcing the verbal attempt contingently; (4) interspersing maintenance and acquisition trials; and (5) using natural reinforcers (Koegel and Koegel 2006). The mean fidelity of implementation score for the non-embedded condition was $99 \%$ (range 96-100\%) and the mean for the embedded social condition was $97 \%$ (range $94-100 \%$ ).

\section{Procedure}

Prior to the start of the study, child-preferred items and activities were determined for each child using the procedures described in the experimental conditions below. All sessions were conducted once a week for $\sim 2 \mathrm{~h}$ in the children's homes. During these sessions, language opportunities were presented. Language opportunities were recorded from the videotaped sessions. An opportunity was defined as each time the adult presented a potential reinforcer and attempted to entice the child to request it. In each session, following a 10-min warm-up period, a 10-min video clip probe of the adult-child interaction was recorded for data analysis of the dependent measures for each condition.

\section{Experimental Conditions}

The study examined the differences in child initiated social behaviors within two experimental conditions: the nonembedded reinforcer condition and the embedded social condition. Both conditions used a Pivotal Response Treatment paradigm to set up and reinforce language opportunities. A language opportunity was defined as any bid made by the clinician with the goal of having the child respond verbally. In both conditions, the interaction took place in the following format: (1) the clinician or parent set up a language opportunity by presenting a discriminative stimulus (e.g., enticing the child with a preferred or child-selected stimulus); (2) the child made a verbal response; and (3) the child's verbal response was reinforced with delivery of the preferred stimulus. Following a brief time for the child to enjoy the reinforcer, another opportunity was created.

\section{Non-embedded Reinforcer Condition}

In this condition, a child's verbal responses were reinforced by providing access to child-preferred toys and activities naturally related to the child's verbalization. An example of this type of opportunity was when an adult stood in front of a child preferred trampoline, and then provided the child with the opportunity to jump on the trampoline after the child said "jump." Another example was when the adult held up a preferred toy truck, and gave the truck to the child after the child said "truck." The specific reinforcers varied within each session according to their interests and were selected from a large pool of available objects selected through a combination of parent report and observations of each child's play preferences. For examples, see Table 1 .

\section{Embedded Social Condition}

In the embedded social condition a social interaction was embedded into the above child-preferred reinforcers. For example, if the child's requested reinforcer was to jump on a trampoline, when the child said "jump," the clinician jumped on the trampoline with the child. For other examples, see Table 1 .

In both conditions, the number of opportunities (see definition of opportunity at the start of the "Procedure" section) provided to request a reinforcer were kept approximately equal to ensure that changes in child social behavior were not 
Table 1 Examples of non-embedded reinforcement versus embedded social reinforcement opportunities

\begin{tabular}{|c|c|c|}
\hline Activity and child behavior & $\begin{array}{l}\text { Non-embedded reinforcement } \\
\text { consequence }\end{array}$ & $\begin{array}{l}\text { Embedded social reinforcement } \\
\text { consequence }\end{array}$ \\
\hline $\begin{array}{l}\text { Bouncing on a trampoline } \\
\text { Child says "jump" }\end{array}$ & $\begin{array}{l}\text { Child is given the opportunity to jump on } \\
\text { the trampoline }\end{array}$ & Adult jumps with the child \\
\hline $\begin{array}{l}\text { Listening to a preferred movie soundtrack } \\
\text { Child requests "music" }\end{array}$ & $\begin{array}{l}\text { Adult starts the video and allows the child } \\
\text { to hear the preferred song }\end{array}$ & Adult sings the preferred song to the child \\
\hline $\begin{array}{l}\text { Playing on a preferred swing } \\
\text { Child requests "swing" }\end{array}$ & $\begin{array}{l}\text { Child is given the opportunity to play on } \\
\text { the swing }\end{array}$ & Adult pushes the child on the swing \\
\hline $\begin{array}{l}\text { Playing in the bathtub } \\
\text { Child requests "splash" }\end{array}$ & $\begin{array}{l}\text { Child is given the opportunity to splash } \\
\text { around }\end{array}$ & Adult splashes the child \\
\hline $\begin{array}{l}\text { Playing with a blanket } \\
\text { Child requests "blanket" }\end{array}$ & $\begin{array}{l}\text { Child is given a preferred blanket to wrap } \\
\text { around themselves }\end{array}$ & Adult wraps the blanket around the child \\
\hline
\end{tabular}

due to differences in total opportunities across condition. Child One was provided with a mean of 52.5 opportunities (range of 33-60) in the non-embedded condition, and a mean of 55.3 opportunities (range of 42-68) in the embedded social condition. Similarly, Child Two was provided with a mean of 46.7 opportunities (range 39-56) and 48.5 opportunities (range of 34-64) in the non-embedded and embedded social conditions, respectively. Finally, Child Three was provided with a mean of 43.6 opportunities (range of 32-52) and 43.8 (37-54) opportunities in the non-embedded and embedded social conditions, respectively.

\section{Dependent Variables}

Several dependent variables were used to assess whether the embedded social condition had an effect on the child's self-initiated social behavior.

\section{Reinforcer Strength (Opportunities with Child Requesting Reinforcer)}

In order to insure comparable reinforcer strength across conditions, the number of trials in which the child had an opportunity to request a reinforcer (i.e., a reinforcer was presented), and did request the reinforcer, were divided by the total number of opportunities the child had to request a reinforcer but did not request the reinforcer in order to yield a percentage.

\section{Self-initiated Social Engagement During Communication}

During the children's verbal requests social engagement was recorded if the child also: (1) physically oriented toward the adult; and/or (2) directed affect (smiled, laughed) toward the adult. This was only recorded during the verbal request, and not during the provision of the reinforcer, in order to not confound affect related to the reinforcer delivery. Using Noldus Observer computerbased scoring software, sessions were scored in $10 \mathrm{~s}$ intervals for the occurrence versus non-occurrence of social engagement. Ten second intervals were selected because the children sometimes initiated verbal requests for reinforcers that frequently during both conditions. During the occasional interval ( $<3 \%$ of total intervals) in which the child was temporarily off-camera data were not recorded. The number of intervals with social engagement was divided by the total number of session intervals to determine the percentage of intervals the child initiated social engagement during communication.

\section{Nonverbal Dyadic Orienting}

Because children with autism frequently avoid eye contact during social interactions (as was the case with the participants in this study), we wished to assess their eye contact during interactions initiated by the adult in this experiment. Dyadic orienting was selected as a nonverbal measure of the children's engagement and was defined as the child looking at the adult's eyes following an action by that adult.

\section{General Child Affect}

In order to assess the child's general level of affect (as opposed to affect just during communication), the first 5-min of each video probe was scored using a 6-point Likert rating scale. This scale consisted of two subscales rating the child's (1) interest in the activity; and (2) happiness. The child's final affect composite score for the session probe was determined by averaging the two affect subscale scores for the entire $5 \mathrm{~min}$ session. Scores of 0 and 1 indicated negative affect, scores of 2 and 3 indicated neutral affect, and scores of 4 or 5 indicated positive affect (see Table 2 for a detailed description of the affect composites). 
Table 2 General child affect rating scales (interest and happiness)

\begin{tabular}{|c|c|c|}
\hline \multicolumn{3}{|l|}{ Interest } \\
\hline Disinterested $(0-1)$ & Neutral Interest (2-3) & Interested (4-5) \\
\hline $\begin{array}{l}\text { Child looks bored, uninvolved, not } \\
\text { curious or eager to continue activity. May } \\
\text { yawn or try to avoid the situation. Spends } \\
\text { much time looking around and not } \\
\text { attending to task. If child does responds } \\
\text { may be long response latency (Score } 0-1 \text {, } \\
\text { depending on extent of disinterest) }\end{array}$ & $\begin{array}{l}\text { Neither particularly interested nor } \\
\text { disinterested. Child seems to passively } \\
\text { accept situation. Does not rebel but is } \\
\text { not eager to continue (Score } 2-3 \text {, } \\
\text { depending on extent of interest) }\end{array}$ & $\begin{array}{l}\text { Attends readily to task. Responses readily } \\
\text { and willingly. Child is alert and involved } \\
\text { in activity (Score } 4-5 \text {, depending on level } \\
\text { of alertness and involvement) }\end{array}$ \\
\hline \multicolumn{3}{|l|}{ Happiness } \\
\hline Unhappy $(0-1)$ & Neutral $(2-3)$ & Happy (4-5) \\
\hline $\begin{array}{l}\text { Cries, pouts, tantrums, appears to be sad, } \\
\text { angry, or frustrated. Child seems not to be } \\
\text { enjoying self (Score } 0-1 \text {, depending on } \\
\text { extent of unhappiness) }\end{array}$ & $\begin{array}{l}\text { Does not appear to be decidedly happy } \\
\text { or particularly unhappy. May smile or } \\
\text { frown occasionally but overall, seems } \\
\text { rather neutral in this situation (Score } \\
2-3 \text {, depending on extent of } \\
\text { happiness) }\end{array}$ & $\begin{array}{l}\text { Smiles, laughs appropriately, seems to be } \\
\text { enjoying self (Score } 4-5 \text {, depending on } \\
\text { extent of enjoyment) }\end{array}$ \\
\hline
\end{tabular}

\section{Reliability}

Two independent observers, one of whom was naïve to the hypothesis of the study, recorded data for all dependent measures for each child. Reliability was scored for $\sim 30 \%$ of all sessions. Cohen's kappa was also calculated to correct for chance agreement. To control for observer drift, videotapes of the sessions were scored in random order.

For the reinforcer strength measure (opportunities with the child requesting for the reinforcer), an agreement was defined as both observers recording an occurrence of a child responding to a language opportunity with a verbal request for the reinforcer. A disagreement was defined as only one observer recording a verbal request for the reinforcer, and the other observer recording no request. Mean percent agreement was 98\%, with a range of 95-100\%). For the reinforcer strength measure, Kappa was calculated at .91. For the self-initiated social engagement during communication measure, an agreement was defined as a 10-s interval in which both raters identically scored either the occurrence or nonoccurrence of social engagement. Mean percent agreement for social engagement intervals was $82 \%$, with a range of $67-100 \%$. Kappa for this measure yielded a score of .64. For the nonverbal dyadic orienting measure, an agreement was defined as any interval that both raters identically scored either an occurrence or nonoccurrence of eye contact in response to an adult action. The mean percent agreement for nonverbal dyadic orienting was $89 \%$, with a range of $71-100 \%$. Kappa for nonverbal dyadic orienting measure was .78 . For general child affect, agreement was defined as observers recording an affect rating within the same affective category (negative, neutral, or positive). Total percent agreement for child affect was $94 \%$, with a range of $88-100 \%$. Kappa for general child affect was .87 .

\section{Results}

Reinforcer Strength (Opportunities with Child Requesting for Reinforcer)

The results of the reinforcer strength measure are shown in Fig. 1. The data show that the strength of the reinforcers were comparable across conditions. Child One responded with a mean of $82 \%$ in the non-embedded condition, and a mean of $88 \%$ in the embedded condition. Child Two responded at a comparable level across both conditions (with a mean of $74 \%$ in the non-embedded condition and a mean of $75 \%$ in the embedded condition). Finally, Child Three responded with a mean of $81 \%$ in the non-embedded condition and a mean of $74 \%$ in the embedded social condition.

In contrast to the relatively equal responding with requests for the reinforcers in the two conditions, large differences in responding occurred on all three social dependent measures for all three participants.

\section{Self-initiated Social Engagement During Communication}

Results are shown in Figs. 1 and 2 for the social engagement measure. In the non-embedded condition, Child One exhibited self-initiated social engagement during communication for a mean of $6 \%$ of intervals across all probes. In 
Fig. 1 Comparison of reinforcer strength, social engagement during communication, and nonverbal dyadic orienting results in the embedded social and the nonembedded conditions for all children
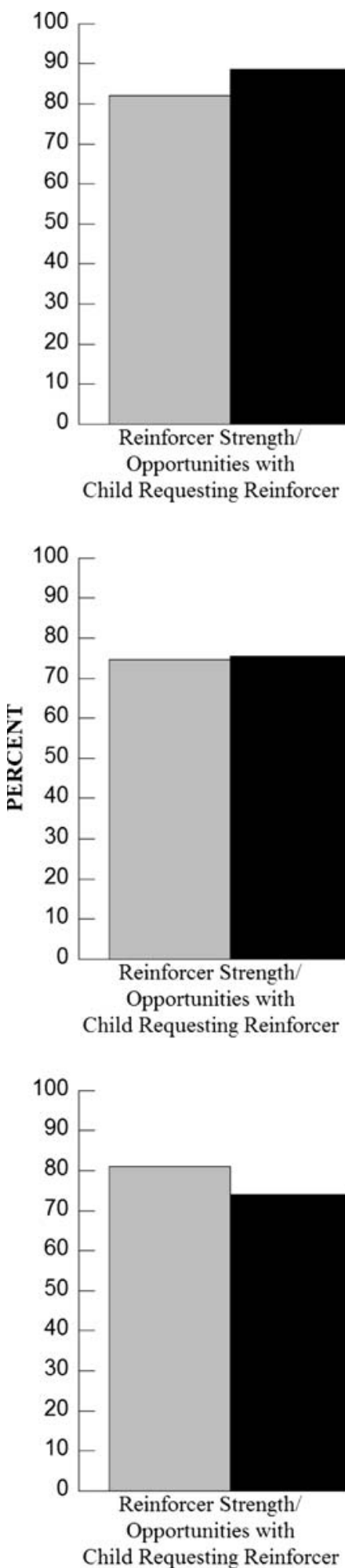

\section{CHILD TWO}

Intervals with

Social Engagement

During Communication

Intervals with
Nonverbal

Dyadic Orienting

CHILD THREE

$\square$ Non-Embedded Condition
$\square$ Embedded Social Condition

$\square$ Non-Embedded Condition contrast, during the embedded social condition, his engagement increased to a mean of $81 \%$ across probes. In the initial non-embedded probe, Child One exhibited no social engagement during communication. With the introduction of the embedded social interaction condition, the levels of social engagement during communication increased to 90 and $71 \%$ of the intervals over the next two probes. The reintroduction of the non-embedded condition was accompanied by a drop in social engagement levels to 9 and $7 \%$ of intervals. The final embedded social condition 
Fig. 2 Percentage of $10-\mathrm{s}$ intervals with social engagement during communication and nonverbal dyadic orienting for all children in the embedded social and nonembedded conditions
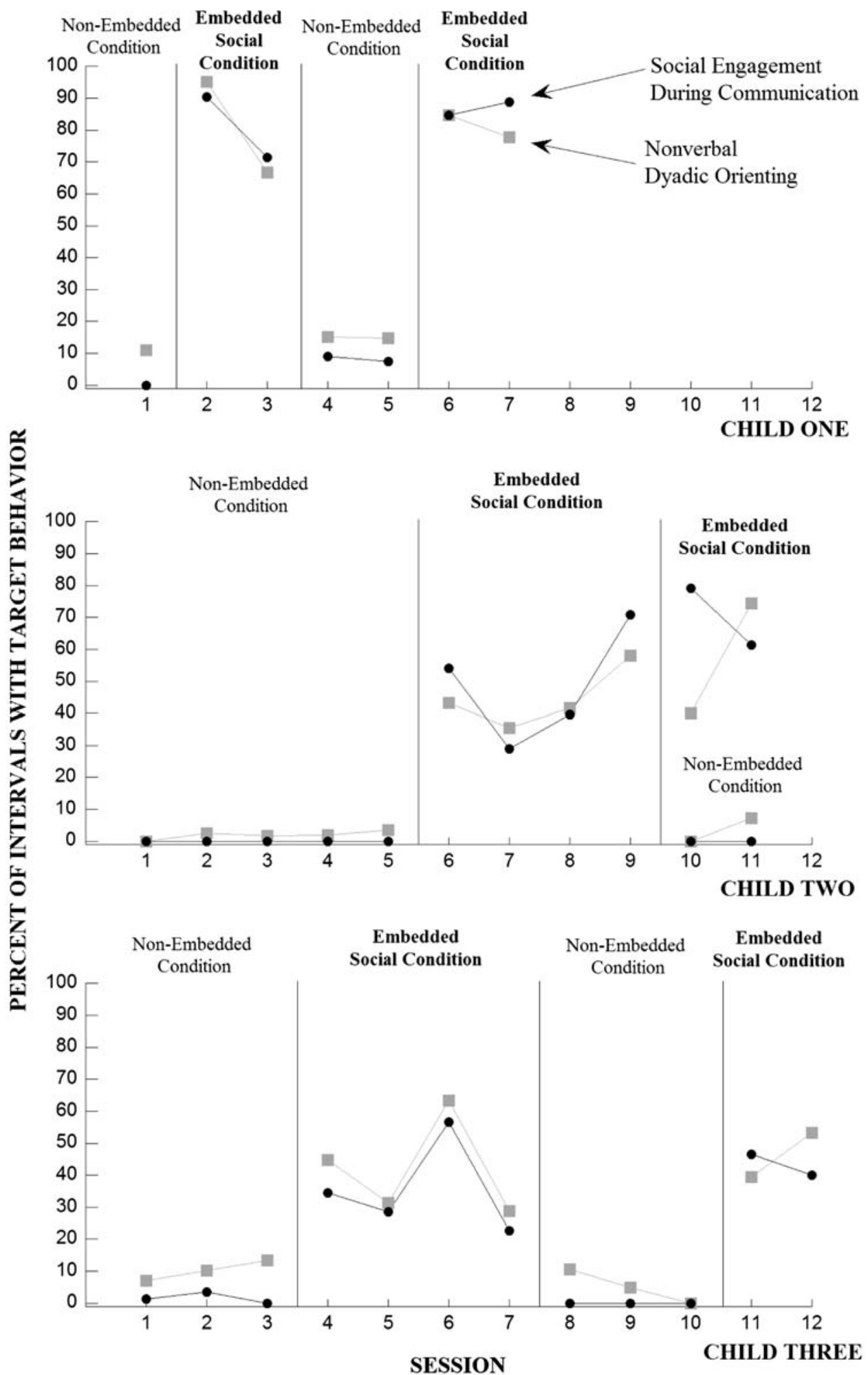

phase resulted in social engagement during communication for 85 and $89 \%$ of the intervals.

Child Two exhibited no social engagement during communication across all non-embedded probes and a mean of $56 \%$ of the intervals during the embedded social condition probes. Specifically, in the five initial non-embedded probes, Child Two did not exhibit any social engagement during communication. Following the introduction of the embedded social condition, Child Two's social engagement during communication increased to $54,29,40$, and $40 \%$ of 
the probes, respectively. During the last two sessions, the embedded and nonembedded conditions were implemented within the same session within an alternating treatments design. During the embedded social phases of these probes, Child Two exhibited social engagement during communication in 79 and $61 \%$ of the intervals, respectively. During the non-embedded phases of these same probes, Child Two did not exhibit any social engagement.

Child Three's data were consistent with the other two children, exhibiting social engagement with a mean of $1 \%$ of intervals during the non-embedded probes and $38 \%$ of probes in the embedded condition. During the first three non-embedded probes, Child Three exhibited social engagement during communication in 2,3 , and $0 \%$ of the intervals, respectively. With the introduction of the embedded condition, the child's engagement during communication increased to $35,29,57$, and $23 \%$ of intervals, respectively. Following the return to the non-embedded condition, no social engagement during communication was observed for the next three sessions. In the final two embedded condition probes, Child Three increased to 47 and $40 \%$ of the intervals, respectively.

\section{Nonverbal Dyadic Orienting}

Results of the nonverbal dyadic orienting measure are also shown in Figs. 1 and 2. All children demonstrated increased levels of nonverbal dyadic orienting during the embedded condition. Specifically, Child One engaged in nonverbal dyadic orienting for a mean of $14 \%$ of intervals in the non-embedded reinforcement condition and $81 \%$ of intervals in the embedded condition. In the first nonembedded condition probe Child One exhibited nonverbal dyadic orienting during $11 \%$ of the intervals. In the embedded social condition probes that followed, the child's nonverbal dyadic orienting increased to 95 and $67 \%$ of the intervals. With the return to the non-embedded condition, dyadic orienting dropped to 15 and $15 \%$ of the intervals. In the final embedded condition, nonverbal dyadic orienting occurred at 85 and $78 \%$ of the intervals.

Child Two exhibited nonverbal dyadic orienting for a mean of $2 \%$ of intervals (across all non-embedded condition probes) and $49 \%$ (across all embedded probes). Specifically, during the first five embedded social condition probes, Child Two engaged in nonverbal dyadic orienting during 3, 2, 2, and 3\% of the intervals, respectively. During the embedded social reinforcement condition, the levels of nonverbal dyadic orienting increased to $43,36,42$, and $58 \%$ of the intervals. During the combined embedded/nonembedded session, nonverbal dyadic orienting occurred during 40 and $73 \%$ of the embedded social phase of the probes and for 0 and $7 \%$ of the non-embedded phase of the same probes, respectively.
Child Three's nonverbal dyadic orienting occurred for a mean of $8 \%$ of intervals across all non-embedded condition intervals and $44 \%$ of the embedded condition intervals. During the first three non-embedded condition probes, he exhibited nonverbal dyadic orienting for 7,10 , and $13 \%$ of the intervals. In the next four embedded probes, nonverbal dyadic orienting increased to $45,31,63$, and $29 \%$ of the intervals, respectively. With the reintroduction of the nonembedded condition, nonverbal dyadic orienting levels dropped to 11,5 , and $0 \%$ during the next three probes. With the reintroduction of the embedded condition, nonverbal dyadic orienting increased, to 40 and $53 \%$ of the intervals, respectively.

\section{General Child Affect}

Results of general child affect are shown in Fig. 3. Child One was rated as exhibiting negative or neutral affect $(2.2$ mean affect rating) across all non-embedded condition probes, and positive affect ( 4.4 mean rating) across the embedded condition probes. Specifically, in the first nonembedded probe, the child's composite affect score was scored as 1 , indicating that his affect was in the negative range. In the following two embedded social condition probes, the child's affect rating increased to 5 and 4.5 , indicating that his affect was in the positive range. Following the reintroduction of the non-embedded condition, the ratings fell to 3 and 2.5, which was in the neutral range. During the final two embedded condition probes, the composite affect scores were 4 and 4 , indicating that affect was in the positive range.

Child Two was scored having neutral affect during the non-embedded condition, with a mean score of 2.6, and positive affect during the embedded social condition, with a mean score of 4.5. Specifically, Child Two's scores were $3,2.5,2.5,3$, and 3 , respectively, which were all in the neutral affect range during the non-embedded probes. With the introduction of the embedded social condition the composite affect scores increased to 5, 5, 4, and 4.5, which were all in the positive range. In the combined embedded social/non-embedded condition probes, the embedded condition phases were rated as 4.5 and 4 , indicating positive affect, while the non-embedded condition phases of the probes received ratings of 2.5 and 2 , respectively, indicating neutral affect.

Child Three exhibited a similar pattern, exhibiting neutral affect during the non-embedded condition, with mean composite score of 2.6, and positive affect during the embedded condition, with a mean score of 3.9. Specifically, in the first three non-embedded probes, the child received affect composite scores of 2, 2.5, and 2.5, which were all in the neutral range. Following the introduction of the embedded social condition, affect scores increased to 4 , 
Fig. 3 General child affect composite ratings for all children in the embedded social and non-embedded conditions
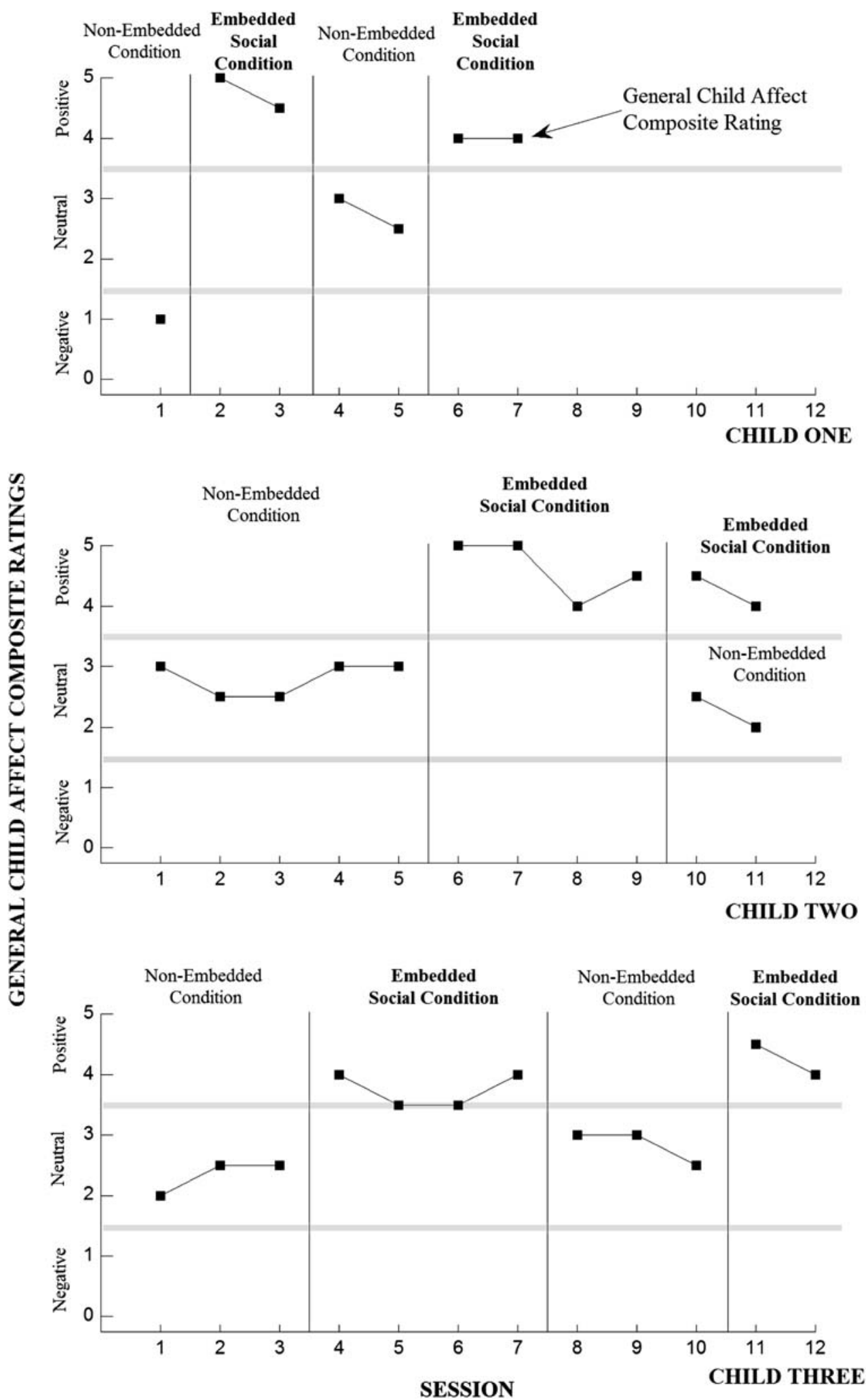

3.5, 3.5, and 4, which were all in the positive range. With the reintroduction of three non-embedded probes, affect scores dropped to 3,3 , and 2.5 , again in the neutral range.
During the final two embedded condition probes, the child's affect scores increased to 4.5 and 4, showing positive affect. 


\section{Effect Size}

Effect size (Cohen's $d$ ) was calculated for social engagement during communication and nonverbal dyadic orienting for all children using the standard mean difference method (Busk and Serlin 1992). Using Cohen's (1988) standards, an effect size of 0.2 is indicative of a small effect, 0.5 a medium and 0.8 a large effect size. Cohen's $d$ for social engagement during communication showed a large effect size for all three participants (Child One $d=11.2$, Child Two $d=4.2$, and Child Three $d=4.3$ ). Similarly, there was a large effect size for nonverbal dyadic orienting for all three participants (Child One $d=7.8$, Child Two $d=3.6$, and Child Three $d=4.4$ ). Finally, for general child affect, Cohen's $d$ was indicative of a large effect size (Child One $d=2.9$, Child Two $d=4.3$, and Child Three $d=3.5$ ).

\section{Discussion}

The data from the experiment show that the sessions with embedded social interactions resulted in increased levels of child initiated social engagement during communication, improved nonverbal dyadic orienting, and higher ratings of overall child affect compared to the non embedded conditions. These findings have both theoretical and applied implications.

Some professionals have suggested that autism is primarily a social disorder, with the lack of appropriate social development leading to the secondary delays in communication and the acquisition of unusual behavioral tendencies (Garfin and Lord 1986; Koegel et al. 1994; Walters et al. 1990). For example, appropriate social coordination behaviors appear to be an important part of language development (Adamson and Bakeman 1985; Bakeman and Adamson 1986). Because early socialization has implications for later developing communication and behavior skills, correcting these apparent social deficits may simultaneously improve impairments in other domains associated with ASDs.

Coordinated eye contact behaviors, such as joint attention (Mundy and Crowson 1997; Warreyn et al. 2005; Whalen et al. 2006) and dyadic orienting (Leekam and Ramsden 2006; Striano and Rochat 1999) have been discussed frequently in the literature. Joint attention has been discussed as an important precursor to communication, and the possibility of improvements in this area resulting in collateral gains in untargeted areas of functioning. It appears that in typical children triadic joint attention is built upon earlier developing dyadic orienting between infant and adult (Bruner 1975; Trevarthen and Hubley 1978; Vygotsky 1978; Werner and Kaplan 1963). Developing methods for evoking dyadic orienting from children with autism may help to establish a foundation in which children with autism find it reinforcing to socialize with others.

Because we were able to evoke self-initiated social behaviors from the participants, this research suggests that embedding motivating social interactions into the intervention may be a successful method for improving children's social areas. Several researchers have explored methods for systematically teaching joint attention to children with autism (e.g., Jones et al. 2006; Whalen and Schreibmen 2003). This study reveals the potential of a specific intervention strategy that appears to be particularly effective with children who demonstrate very low levels of social engagement during intervention. Social embedding may serve as an intervention that indirectly evokes child initiated social behavior, rather than directly teaching social behaviors. This may have theoretical implications, as it suggests that the ability for social interaction were present all along. Developing methods for tapping into "dormant" social areas may hold a key to returning children with autism to a more typical social developmental trajectory.

In these embedded social reinforcement interactions, the communicative partners are serving as sources of reinforcement, as opposed to the sole provision of items or activities, mirroring how typical children perceive others (i.e., their partners' interactions are rewarding as sources of enjoyment, comfort, and companionship). By embedding social interaction into the intervention, children with autism may be more motivated to seek out and engage with other people. The practical applications of these findings are that there is a rapid emergence of social behavior under these conditions. This may have a positive transactional effect on the motivation of the child and the adults involved in the intervention. It is interesting to note, that in the present study the experimental condition was implemented infrequently, and there was little carryover after the intervention was terminated. Current research in our Center (e.g., Vernon 2009) suggests that more frequent presentations of the intervention, such as within a parent education program, result in a more generalized benefit. Overall, the present study provides a step toward identifying variables that may be especially promising for research on social engagement for children with autism.

Acknowledgments The authors would like to acknowledge and thank all of the undergraduate research assistants and families that assisted and participated in this project. Preparation of this manuscript and support for the research leading to it were provided by Research Grants MH28210 from the National Institute of Mental Health, and by the Eli and Edythe L. Broad Foundation.

Open Access This article is distributed under the terms of the Creative Commons Attribution Noncommercial License which permits any noncommercial use, distribution, and reproduction in any medium, provided the original author(s) and source are credited. 


\section{References}

Adamson, L. B., \& Bakeman, R. (1985). Affect and attention: Infants observed with mothers and peers. Child Development, 56, 582 593. doi: $10.2307 / 1129748$.

American Psychiatric Association. (2000). Diagnosistic and statistical manual of mental disorders (4th ed.). Washington, DC: Author. text revision.

Bakeman, R., \& Adamson, L. B. (1986). Infants' conventionalized acts: Gestures and words with mothers and peers. Infant Behavior and Development, 9, 215-230. doi:10.1016/0163-6383 (86)90030-5

Barlow, D. H., \& Hersen, M. (1984). Single case experimental design: Strategies for studying behavior change (2nd ed.). New York: Pergamon.

Bruner, J. S. (1975). From communication to language: A psychological perspective. Cognition, 3, 255-287. doi:10.1016/00100277(74)90012-2.

Busk, P. L., \& Serlin, R. C. (1992). Meta-analysis for single-case research. In T. R. Kratochwill \& J. R. Levin (Eds.), Single-case research designs and analysis: New directions for psychology and education (pp. 187-212). Hillsdale, NJ: Lawrence Erlbaum Associates.

Charman, T., Baron-Cohen, S., Swettenham, J., Baird, G., Drew, A., \& Cox, A. (2003). Predicting language outcome in infants with autism and pervasive developmental disorder. International Journal of Language \& Communication Disorders, 38, 265285. doi:10.1080/136820310000104830.

Cohen, J. (1988). Statistical power analysis for the behavioral sciences (2nd ed.). Hillsdale, NJ: Lawrence Earlbaum Associates.

Garfin, D. G., \& Lord, C. (1986). Communication as a social problem in autism. In E. Schoplet \& G. B. Mesibov (Eds.), Social behavior in autism (pp. 133-152). New York: Plenum Press.

Goetz, L., Schuler, A., \& Sailor, W. (1979). Teaching functional speech to the severely handicapped: Current issues. Journal of Autism and Developmental Disorders, 9, 325-343. doi:10.1007/ BF01531443.

Harris, S. L., \& Weiss, M. J. (2007). Right from the start: Behavioral intervention for young children with autism. Topics in Autism. Bethesda, MD: Woodbine House.

Jones, E. A., Carr, E. G., \& Feeley, K. M. (2006). Multiple effects of joint attention intervention for children with autism. Behavior Modification, 30, 782-834. doi:10.1177/0145445506289392.

Joseph, R. M., \& Tager-Flusberg, H. (1997). An investigation of attention and affect in children with autism and Down's syndrome. Journal of Autism and Developmental Disorders, 27, 385-396. doi:10.1023/A:1025853321118.

Kanner, L. (1943). Autism disturbances of affective contact. The Nervous Child, 2, 217-250.

Koegel, R. L., Dyer, K., \& Bell, L. K. (1987a). The influence of childpreferred activities on autistic children's social behavior. Journal of Applied Behavior Analysis, 20, 243-252. doi:10.1901/jaba. 1987.20-243

Koegel, R. L., \& Koegel, L. K. (2006). Pivotal response treatments for autism: Communication, social, and academic development. Baltimore, MD: Paul H Brookes Publishing.

Koegel, L. K., Koegel, R. L., Harrower, J. K., \& Carter, C. M. (1999). Pivotal response intervention I: Overview of approach. The Journal of the Association for Persons with Severe Handicaps, 24, 174-185. doi:10.2511/rpsd.24.3.174.

Koegel, R. L., Koegel, L. K., \& Surratt, A. V. (1992). Language intervention and disruptive behavior in preschool children with autism. Journal of Autism and Developmental Disorders, 22, 141-153. doi:10.1007/BF01058147.
Koegel, L. K., \& LaZebnik, C. (2009). Growing up on the spectrum: A guide to life, love, and learning for teens and young adults with autism and Asperger's. New York: Viking Penguin.

Koegel, R. L., O'Dell, M. C., \& Koegel, L. K. (1987b). A natural language teaching paradigm for non-verbal autistic children. Journal of Autism and Developmental Disorders, 17, 187-199. doi:10.1007/BF01495055.

Koegel, L. K., Valdez-Menchaca, M. C., \& Koegel, R. L. (1994). Autism: Social communication difficulties and related behaviors. In V. B. Van Hasselt \& M. Hersen (Eds.), Advanced abnormal psychology (pp. 182-206). New York: Plenum.

Koegel, R. L., \& Williams, J. A. (1980). Direct versus indirect response-reinforcer relationships in teaching autistic children. Journal of Abnormal Child Psychology, 8, 537-547. doi: 10.1007/BF00916505.

Leekam, S. R., \& Ramsden, C. A. H. (2006). Dyadic orienting and joint attention in preschool children with autism. Journal of Autism and Developmental Disorders, 36, 185-197. doi:10.1007/ s10803-005-0054-1.

Lord, C., Risi, S., Lambrecht, L., Cook, E. H., Leventhal, B. L., \& DiLavore, P. C. (2000). The autism diagnostic observation schedule-generic: A standard measure of social and communication deficits associated with the spectrum of autism. Journal of Autism and Developmental Disorders, 30(3), 205-223. doi: 10.1023/A:1005592401947.

Lord, C., Rutter, M., \& Le Couteur, A. (1994). Autism diagnostic interview-revised: A revised version of a diagnostic interview for caregivers of individuals with possible pervasive developmental disorders. Journal of Autism and Developmental Disorders, 24(5), 659-685. doi:10.1007/BF02172145.

Lovaas, O. I. (1987). Behavioral treatment and normal educational and intellectual functioning in young autistic children. Journal of Consulting and Clinical Psychology, 55, 3-9. doi:10.1037/0022006X.55.1.3

McGee, G. G., Morrier, M. J., \& Daly, T. (1999). An incidental teaching approach to early intervention for toddlers with autism. The Journal of the Association for Persons with Severe Handicaps, 24, 133-146. doi:10.2511/rpsd.24.3.133.

Mundy, P., \& Crowson, M. (1997). Joint attention and early social communication: Implications for research on intervention with autism. Journal of Autism and Developmental Disorders, 27, 653-676. doi:10.1023/A:1025802832021.

Mundy, P., \& Sigman, M. (1989). Specifying the nature of social impairment in autism. In G. Dawson (Ed.), Autism: Nature, diagnosis, and intervention (pp. 3-21). New York: Guilford.

Mundy, P., Sigman, M., \& Kasari, C. (1990). A longitudinal study of joint attention and language development in autistic children. Journal of Autism and Developmental Disorders, 20, 115-128. doi:10.1007/BF02206861.

Prizant, B. M., Wetherby, A. M., Rubin, E., Laurent, A. C., \& Rydell, P. J. (2006). The SCERTS model: A comprehensive educational approach for children with autism spectrum disorders (Vol. 1). Baltimore, MD: Paul H Brookes Publishing.

Skinner, B. F. (1982). Contrived reinforcement. The Behavior Analyst, 5(1), 3-8.

Sparrow, S., Balla, D., \& Cicchetti, D. (1984). Vineland adaptive behavior scales (survey form). Circle Pines, Minnesota: American Guidance Service.

Striano, T., \& Rochat, P. (1999). Developmental link between dyadic and triadic social competence in infancy. The British Journal of Developmental Psychology, 17, 551-562. doi:10.1348/ 026151099165474.

Trevarthen, C., \& Hubley, P. (1978). Secondary intersubjectivity: Confidence, confiding and acts of meaning in the first year. In A. Lock (Ed.), Action, gesture and symbol. London: Academic Press. 
Vernon, T. W. (2009). Assessing the transactional benefits of parentdelivered embedded social interactions with children with autism. Unpublished doctoral dissertation, University of California, Santa Barbara.

Volkmar, F. R., \& Klin, A. (1994). Social development in autism: Historical and clinical perspectives. New York, NY: Oxford University Press.

Vygotsky, L. S. (1978). Mind in society: The development of higher mental functions. Cambridge, MA: Harvard University Press.

Walters, A. S., Barrett, R. P., \& Feinstein, C. (1990). Social relatedness and autism: Current research, issues, directions. Research in Developmental Disabilities, 11, 303-326. doi: 10.1016/0891-4222(90)90015-Z.

Warreyn, P., Roeyers, H., Oelbrandt, T., \& De Groote, I. (2005). What are you looking at? Joint attention and visual perspective taking in young children with autism spectrum disorder. Journal of Developmental and Physical Disabilities, 17, 55-73. doi: 10.1007/s10882-005-2201-1.

Werner, H., \& Kaplan, B. (1963). Symbol formation. Oxford, England: Wiley.

Whalen, C., Schreibman, L., \& Ingersoll, B. (2006). The collateral effects of joint attention training on social initiations, positive affect, imitation, and spontaneous speech for young children with autism. Journal of Autism and Developmental Disorders, 36, 655-664. doi:10.1007/s10803-006-0108-z.

Whalen, C., \& Schreibmen, L. (2003). Joint attention training for children with autism using behavior modification procedures. Journal of Child Psychology and Psychiatry and Allied Disciplines, 44, 456-468. doi:10.1111/1469-7610.00135.

Williams, J. A., Koegel, R. L., \& Egel, A. L. (1981). Responsereinforcer relationships and improved learning in autistic children. Journal of Applied Behavior Analysis, 14, 53-60. doi: 10.1901/jaba.1981.14-53.

Wimpory, D. C., Hobson, R. P., Williams, J. M. G., \& Nash, S. (2000). Are infants with autism socially engaged? A study of recent retrospective parental reports. Journal of Autism and Developmental Disorders, 30, 525-536. doi:10.1023/A: 1005683209438.

Yoder, P., \& Stone, W. L. (2006). Randomized comparison of two communication interventions for preschools with autism spectrum disorders. Journal of Consulting and Clinical Psychology, 74, 426-435. doi:10.1037/0022-006X.74.3.426.

Zwaigenbaum, L., Bryson, S., Rogers, T., Roberts, W., Brian, J., \& Szatmari, P. (2005). Behavioral manifestations of autism in the first year of life. International Journal of Developmental Neuroscience, 23, 143-152. doi:10.1016/j.ijdevneu.2004.05.001. 